\title{
SOBRE LA NECESIDAD DE INTRODUCIR LA PERSPECTIVA DE GÉNERO EN LA JURISDICCIÓN CIVIL ESPAÑOLA
}

\section{THE URGE FOR GENDER PERSPECTIVE IN THE SPANISH CIVIL JURISDICTION}

\section{Mónica GARCÍA GOLDAR}

Author / Autora:

Mónica García Goldar

Universidade de Santiago de Compostela

Santiago de Compostela, Spain

monica.garcia@usc.es

https://orcid.org/0000-0002-3235-292X

Submitted / Recibido: 24/09/2020

Accepted / Aceptado: 22/10/2020

To cite this article / Para citar este artículo: García Goldar, M. (2021). Sobre la necesidad de introducir la perspectiva de género en la jurisdicción civil española. Feminismo/s, 38, 307-329. https://doi.org/10.14198/ fem.2021.38.12

Licence / Licencia:

This work is licensed under a Creative Commons Attribution 4.0 International.

\section{(c) (i)}

(C) Mónica García Goldar

\section{Resumen}

Este estudio pretende demostrar la ausencia de perspectiva de género en la jurisdicción civil española, así como la perpetuación de ciertos estereotipos de género. Para acometer este propósito, se ha elegido un tema que afecta principalmente a las mujeres (los cuidados) y se ha seleccionado una muestra de hasta veinte sentencias jurisprudenciales sobre un ámbito concreto (en este caso, las disposiciones testamentarias en favor de quien cuide al testador). Las conclusiones del análisis son ciertamente alarmantes, por cuanto suponen la constatación de una triste realidad: los cuidados no se valoran siempre con el mismo rigor, sino que se observan importantes diferencias en función del sexo del cuidador. La jurisprudencia española es definitivamente más estricta con las cuidadoras y mucho más laxa con los cuidadores.

Palabras clave: perspectiva de género; jurisdicción civil; mujeres; cuidados.

\section{Abstract}

This study aims to demonstrate the absence of a gender perspective in the Spanish civil 
jurisdiction, as well as the perpetuation of certain gender stereotypes. To achieve this purpose, a topic that mainly affects women has been chosen and a sample of up to twenty jurisprudential rulings on a specific area has been selected (in this case, the testamentary provisions in favor of whoever cares for the testator). The conclusions of the analysis are certainly alarming, since they imply the verification of a sad reality: care is not always valued with the same rigor; important differences are observed regarding the caregiver's sex. Spanish jurisprudence is definitely stricter with female caregivers and much more lax with male caregivers.

Keywords: Gender perspective; Civil jurisdiction; Women; Caregivers.

\section{INTRODUCCIÓN: «LOS CUIDADOS TIENEN ROSTRO DE MUJER»}

El propósito de este trabajo es intentar demostrar la falta de neutralidad en la aplicación de las normas por parte de los tribunales, como ya pudo demostrar hace algunos años Aguilera Rull (2012). Y por ello hemos elegido un tema en el que la perspectiva de género resulta más que evidente: el cuidado de otra persona. Esta materia sigue siendo todavía cosa de mujeres (García Rubio, 2020; Mier Villarías, Romeo Pérez, Canto Combarro y Mier Villarías, 2007, pp. 29-32; Pau Pedrón, 2020, pp. 8, 20 y 23); así lo demuestran los datos: según el estudio «CuidadorES», realizado por la Sociedad Española de Geriatría y Gerontología en colaboración con Lindor, en 2016, el 89\% de los cuidadores eran mujeres. Los datos no parecen haber cambiado recientemente, pues según noticia publicada por la Cruz Roja, con datos de la Sociedad Española de Geriatría y Gerontología y el Consejo Superior de Investigaciones Científicas (CSIC), en el año 2018, de nuevo, el 89\% de cuidadores eran mujeres, razón por la que afirman que «los cuidados tienen rostro de mujer».

No importa si se trata de cuidados formales (profesionales o no, pero remunerados) o cuidados informales, pues en todos ellos se observa la «feminización del cuidado» ${ }^{1}$. Lo único que cambia es el perfil de la cuidadora: la cuidadora formal profesional suele ser una mujer de entre 20 y 30 años, soltera y sin hijos, diplomada en Enfermería; la cuidadora formal no profesional es habitualmente una mujer inmigrante de entre 30 y 40 años, soltera y sin

1. Expresión utilizada por Red2Red Consultores, 2008, p. 39.

Feminismo/s 38, July 2021, 307-329 
hijos, con un nivel de estudios medio; y, por último, la cuidadora informal es normalmente una mujer de más de 50 años, casada y con hijos, con estudios primarios y sin ocupación laboral remunerada (Red2Red Consultores, 2008, p. 146).

Lo cierto es que la mayoría de los cuidados que se prestan son los informales, realizados en el interior de los hogares. Este cuidado familiar constituye la parte invisible del denominado «iceberg del bienestar», en el que la parte visible corresponde a los servicios formales de cuidado (Rogero García, 2010, p. 48). Así lo demuestra un informe del CSIC titulado «Un perfil de las personas mayores en España, 2015: Indicadores estadísticos básicos» (Abellán García y Pujol Rodríguez, 2015): la persona que «fundamentalmente cuida de los hombres mayores con dependencia es su cónyuge, seguida de su hija. En el caso de las mujeres mayores que necesitan ayuda son las hijas las que fundamentalmente se hacen cargo de los cuidados, seguidas de otros familiares y amigos» (p. 4).

Cabría preguntarse por qué es así; por qué la mayoría de cuidados a otra persona se siguen llevando a cabo por mujeres. La respuesta a este desigual reparto se puede deber a diferentes factores: edad y ciclo de la familia, situación laboral de la mujer, incompatibilidad entre el rol familiar y laboral, o la persistencia de estereotipos de género, como los relativos al trabajo (para ellos, el trabajo asalariado es una obligación y el no remunerado es voluntario; para ellas, el trabajo asalariado es un derecho que pueden ejercer de forma voluntaria y el no remunerado es una obligación) o que las mujeres están dotadas de una manera natural por cualidades como la sensibilidad y la efectividad, lo que las convierte en cuidadoras ideales (Rubio, 2004, p. 47). Estereotipos que, por fortuna, comienzan a desmontarse poco a poco, con la progresiva incorporación de la mujer al mercado laboral y los estudios de género, pero que, sin embargo, no parecen desaparecer de los estándares que aplican los Tribunales; baste señalar, por ejemplo, las altas demandas que se exigen para la atribución de la custodia del descendiente a la «buena madre» (Aguilera Rull, 2012, pp. 190-196).

Para que uno pueda hacerse una mejor imagen de la importancia de los cuidados, cabría recordar que se ha estimado que existen más de cinco millones de mujeres cuidadoras informales en España (Suso Araico y Velasco Gisbert, 2009, p. 76). La cifra no puede en absoluto resultar alarmante: según 
el INE, en abril de 2020 existían más de 9 millones de personas en España con sesenta y cinco o más años de edad, cifra que representa casi el 20\% de la población total. Además, se ha puesto de manifiesto cierta tendencia al «envejecimiento del envejecimiento» (Facal Fondo y Torrens Calle, 2010, p. 70): el 16\% de ese total de 9 millones lo conforman personas de ochenta y cinco años de edad o más (en total, más de un millón y medio).

La importancia económica de los cuidados informales que son llevados a cabo en gran medida por mujeres es, pues, indudable: en el año 2009, un estudio estimó que el cuidado informal representaría el 4\% del PIB nacional en 2006 (Suso Araico y Velasco Gisbert, 2009, p. 78). Tal vez fue esta incipiente percepción acerca de su importancia lo que propició la aprobación de la Ley 39/2006, de 14 de diciembre, de Promoción de la Autonomía Personal y Atención a las personas en situación de dependencia, cuya Disposición Adicional cuarta establece las bases para que reglamentariamente se determine la incorporación a la Seguridad Social de los cuidadores no profesionales. En la actualidad, y desde el pasado uno de abril de 2019, los cuidadores y las cuidadoras no profesionales de beneficiarios de la Ley de Dependencia pueden suscribir un convenio especial con la Seguridad Social para que sus cotizaciones corran a cargo de la Administración General del Estado, según dispone el Real Decreto-ley 6/2019, de 1 de marzo, de medidas urgentes para garantía de la igualdad de trato y de oportunidades entre mujeres y hombres en el empleo y la ocupación.

Pues bien, una vez puesta de manifiesto la evidente feminización de los cuidados informales y su trascendencia en términos económicos, cabe reiterar que el objetivo de este estudio es analizar cuál es la repercusión de aquellos en el ámbito sucesorio y comprobar si existe, o no, perspectiva de género por parte de nuestros juzgados y tribunales al lidiar con esta cuestión.

\section{OBSERVACIONES GENÉRICAS}

Una primera idea que hemos podido extraer del análisis jurisprudencial es que hombres y mujeres disponen cláusulas a favor de quienes los cuidan sin apenas diferencias resaltables (del total de veinte sentencias analizadas, el $40 \%$ se trata de testadores y el $60 \%$ de testadoras). Creemos que no existen, en general, preferencias que guarden relación entre el género del testador y 
el género del cuidador, pues se observa que tanto testadores como testadoras designan a beneficiarios varones o mujeres por igual: de los ocho testadores varones, cuatro designan a un cuidador y cuatro a una cuidadora; de las doce testadoras, cinco designan a un cuidador y cuatro designan a una cuidadora. La única diferencia reseñable es que son las testadoras quienes designan con más frecuencia a los beneficiarios de forma general: en tres de los casos estudiados en que la testadora era mujer, los beneficiarios se habían designado de forma plural, en favor de familiares (hijos, hermanos, sobrinos), pero siempre bajo la condición de que todos o uno de ellos (el beneficiario) la cuidase ${ }^{2}$.

Lo que sí sorprende es, sin embargo, que no se observe una mayor existencia de beneficiarias-mujeres, es decir, de cuidadoras-mujeres, tal y como cabría esperar en atención a los datos ofrecidos con anterioridad (el 89\% de los cuidadores a nivel nacional son mujeres). Esto podría hallar su fundamento en diferentes causas, como la infrarrepresentación ofrecida por las sentencias seleccionadas, o que exista mayor litigiosidad en los casos en que los cuidadores-beneficiarios son varones; sin embargo, ninguno de estos motivos nos parece el correcto. Creemos que probablemente la causa que mejor explique esta falta de correlación entre el género de los cuidadores informales según los datos estadísticos y el género de los cuidadores-beneficiarios en las disposiciones testamentarias que fueron objeto de controversia se encuentra en el hecho de que, con gran frecuencia, estos últimos cuidadores-beneficiarios suelen tratarse de personas del entorno familiar del testador o la testadora (hijo, nieto o sobrino). En nuestra selección de jurisprudencia así puede observarse: todos los beneficiarios varones eran familiares directos, a excepción de un caso, en el que se trataba de sobrino político (desconocemos si se trataba del marido de la sobrina o si era el sobrino del cónyuge supérstite).

Cabe pensar, pues, que los testadores y las testadoras designan como beneficiarios varones a aquellos con los que les unen lazos familiares, aun cuando tal vez no sean ellos quienes efectivamente vayan a dispensar los cuidados, sino su cónyuge u otra persona. Existen tres argumentos que nos

2. Véanse las Sentencias que corresponden con las siguientes referencias: RJ 2010, 269; RJ 2011, 5217; AC 2019, 846. 
pueden ayudar a sostener tal afirmación: por una parte, en algunos de los casos analizados se demuestra que el beneficiario no era quien cuidaba al testador o testadora, sino otra persona. Así, por ejemplo, en el caso anteriormente mencionado, en el que la testadora instituye como heredero a su sobrino político bajo condición de cuidarla (SJPI de Celanova de 22 noviembre de 2012: JUR 2014, 282406), se hace mención expresa a que la misma había sido cuidada desde su traslado a la casa del beneficiario por una señora contratada llamada Ana. En otro caso que comentaremos de forma amplia posteriormente (SAP de A Coruña de 15 de mayo de 2019: AC 2019, 846) se determina que los hijos varones cumplieron con la condición de cuidar a la testadora contratando a dos mujeres cuidadoras.

Por otra parte, ocurre también que en algunos casos es el propio testador o testadora quien designa un beneficiario varón con la condición de que lo cuide personalmente, o pague a otra persona que así lo haga, incluso si es de la familia. Así ocurre, por ejemplo, en el caso del testador Narciso (SAP de Pontevedra de 5 junio de 2003: JUR 2004, 2187), que dispuso el legado de una casa y finca en favor del nieto, sujetándolo a la siguiente condición: «Impone a este nieto legatario, como condición del beneficio en su favor otorgado, las obligaciones, que cumplirá de su exclusiva cuenta, de asistir, cuidar y funerar al testador y a su esposa: o, alternativamente, si por no hacerlo así, cumpliese dichas atenciones alguna hija de estos, a satisfacción de los mismos, hacer pago a esa hija, durante todo el tiempo que realice esas prestaciones, de la suma mensual de veinte mil pesetas, quedando en otro caso sin efecto dicho legado». Lo mismo se puede decir del testamento de Nieves (SAP de Pontevedra de 17 de marzo de 2017: JUR 2018, 1928), en el que instituye heredero a su marido con la obligación personal de cuidarle en casa; y que, «en caso de no poder hacerlo su esposo se contrate a una persona para que la atienda correctamente, negándose a que se le lleve a una residencia o geriátrico».

Finalmente, el tercer argumento es que en los seis casos en los que el legado se hace a una persona «extraña» (no familiar del testador o la testadora $)^{3}$, las beneficiarias sí son mujeres, a quienes se les recompensa por

3. Véanse las Sentencias que corresponden con las siguientes referencias: JUR 2002, 136495; AC 2012, 1285; AC 2018, 1045; JUR 2019, 2021; RJ 1957, 1181; RJ 2018, 2314.

Feminismo/s 38, July 2021, 307-329 
los cuidados ofrecidos o se les designa como beneficiarias de un legado bajo condición de cuidados. En las sentencias analizadas no existe ni un solo caso en el que la persona beneficiaria «extraña» al testador fuese un varón. Pasamos, pues, a analizar brevemente las características de este tipo de legados compensatorios a mujeres cuidadoras.

\section{EN CONCRETO: SENTENCIAS QUE PONEN DE MANIFIESTO LA PERPETUACIÓN DE ESTEREOTIPOS DE GÉNERO POR PARTE DE LOS TRIBUNALES EN RELACIÓN CON LOS CUIDADOS}

En relación con la perspectiva de género en los cuidados al testador, nos ha parecido observar en esta selección de jurisprudencia que las sentencias en las que se juzga el cumplimiento de la condición por el beneficiario varón son más laxas que aquellas en las que se juzga el cumplimiento de la condición por la beneficiaria mujer.

De los seis casos en los que se puso en duda el cumplimiento de la condición de cuidados por parte del beneficiario varón, sólo dos de ellas fueron estimadas, probablemente por la fuerza probatoria que se aprecia en ambas sentencias: en un caso (SAP de Pontevedra de 5 junio de 2003: JUR 2004, 2187), la esposa del testador, como supuesta beneficiaria de los cuidados, otorgó actas notariales en dos ocasiones (y con cinco años de diferencia) manifestando el «incumplimiento de la obligación personal de cuidado» por parte del nieto legatario; en el otro (SAP de Sevilla de 9 junio de 2009: JUR 2010, 14320), y de forma muy similar, la esposa del testador también reconoce en acta notarial que no hubo cumplimiento de la condición de cuidados al causante por parte del sobrino beneficiario ${ }^{4}$.

4. Cabe señalar que en este caso la condición de cuidados establecida para el legado era mucho más específica, pues incluía la obligación de cuidar al testador «durante los últimos años de su vida, alimentándole y dándole habitación, vestimenta, asistencia médica y farmacológica y demás englobadas en el trato personal y enumeradas en el artículo 142 del Código Civil». Probablemente esto también facilitó enormemente la prueba, pues el legatario no tuvo en su compañía a su tío durante los años anteriores ni «realizó con él ningún tipo de cuidado» respecto a todas las cuestiones delimitadas, tal y como se señala en la propia sentencia.

Feminismo/s 38, July 2021, 307-329 
En los cuatro casos restantes, la determinación del cumplimiento de los cuidados resulta un tanto dudosa en nuestra opinión; pasamos pues a ver las sentencias con mayor detalle.

\subsection{Sobre la condición de cuidar y «vivir en compañía del testador»}

En relación con la interpretación que se puede hacer de una cláusula en la que se establezca la obligación de cuidados y de «vivir en compañía del testador», nos gustaría traer a colación la STS de 21 de enero de 2003 (RJ 2003, 604). Este caso trata del testamento otorgado en 1964 por María, en el que ordenaba la mejora y el tercio de libre disposición en favor de su hijo, tras lo cual dispone la siguiente cláusula: «La mejora y el legado de la cláusula anterior los hace a su hijo Antonio, con la obligación modal de cuidar y asistir a la testadora y a su esposo, en cuanto precisen sanos o enfermos, y vivir en su compañía, en familia, ayudándoles, según costumbre, en los trabajos de la casa y laboreo de los bienes». Cabe destacar que la testadora había otorgado otros dos testamentos anteriores: el primero, en 1955, era prácticamente igual al ahora objeto de estudio; el segundo, en 1956, y tras haber emigrado su hijo Antonio a Santo Domingo, hizo idéntica disposición pero en favor de una de sus hijas, aunque en este caso se añadían más obligaciones (la de cuidar al resto de la familia); en concreto, se establecía que la disposición se hacía «a condición de que habrá de asistir y cuidar a su padre en cuanto precise sano o enfermo en tanto se conserve viudo y vivir en su compañía en familia ayudándole según costumbre en los trabajos de la casa y bienes y la de tener con ella también en familia a sus hermanos solteros mientras no se casen o reclamen sus participaciones hereditarias y le ayuden según el estilo del país en las faenas agrícolas y domésticas», previendo, según dice la sentencia, que «si la hija así favorecida no cumpliera por su voluntad las condiciones impuestas o dejara de vivir en compañía de sus padres, los referidos legados y mejora pasarían a otra de sus hijas en las mismas condiciones $y$, en defecto de esta última por las causas expresadas, a otra hija distinta, también en igual forma».

El testamento litigioso de 1964 se otorgó desde que el demandado retornase de Santo Domingo a casa de sus padres en Galicia; sin embargo, y por motivos laborales, volvió a marcharse, esta vez a Cataluña, de donde nunca 
volvió, salvo en vacaciones cuando volvía al pueblo de sus padres, pero para hospedarse en casa de sus suegros. Pues bien, tras el fallecimiento de los progenitores, los otros hermanos impugnaron esa cláusula del testamento, resultando que en primera instancia se desestimó al considerarse que la referida cláusula era modal y no condicional, e interpretando la voluntad de la testadora en función de sus otros dos testamentos anteriores: la testadora se había considerado suficientemente atendida por su hijo mejorado-legatario, por lo que se desestimó la demanda. El tribunal de segunda instancia, razonando que el contenido de la cláusula segunda del testamento era el propio de una condición suspensiva potestativa de hechos pasados y entendiendo que el demandado la había incumplido por propia voluntad al alejarse del domicilio materno en Galicia para fijar su residencia en Cataluña, estimó la demanda y dejó sin efecto la mejora y el legado. Llegado el asunto al Tribunal Supremo, se consideró que efectivamente era un modo y no una condición, estimando así la eficacia de la cláusula impugnada: el hijo emigrado a Cataluña resultó mejorado, a pesar de la falta evidente de cuidados, de no haber vivido en compañía de sus padres, y de no haber ayudado en los «trabajos de casa y laboreo de los bienes».

Creemos que sería conveniente contrastar esta STS de 2003 con la SAP de Asturias de 3 de febrero de 1995 (AC 1995, 393). En este caso, Domingo había otorgado un testamento en 1968 en el que mejoraba a su hija bajo condición de «vivir en compañía del testador y su esposa asistiéndoles y reverenciándoles hasta su fallecimiento» y ordenando también que «como toda la herencia forma una explotación agrícola, se le adjudique íntegramente al que resulte mejorado, el cual separará en metálico a sus hermanos y coherederos en la parte que les corresponde». Las hermanas de la mejorada impugnaron la eficacia de la cláusula, pues consideraron que no se cumplió la condición: la beneficiaria sí había cuidado a sus padres, pero se había trasladado a vivir, a raíz de su matrimonio en 1971, al domicilio de sus suegros, sito en otra localidad distante entre 5 y $12 \mathrm{~km}$, según refiere la sentencia. El padre testador falleció en 1974, sin haber modificado la disposición testamentaria. Pues bien, la Audiencia Provincial termina considerando que «en el supuesto enjuiciado la cláusula sometida a debate entre las partes, en su propia literalidad, claramente evidencia que la real voluntad del testador era la de supeditar la mejora a la convivencia del hijo o hija en que

Feminismo/s 38, July 2021, 307-329 
recayera la misma con el mismo hasta su fallecimiento [«vivir en compañía del testador»], y aunque obviamente las obligaciones establecidas eran más amplias que la mera convivencia, es claro que éstas no se agotaban en las de sola asistencia, cuidado y reverencia, únicas cumplidas por la heredera demandada. En definitiva y como conclusión del tenor literal de tales estipulaciones puede concluirse que la intención del testador no fue sólo la de procurarse la asistencia y cuidados personales de uno de sus hijos en los últimos años de su vida, sino la de mejorar al hijo o hija que estuviera conviviendo en la casa familiar, o cuando menos en lugar próximo a la misma, si no se quiere interpretar el término convivir tan rígidamente, pero en todo caso en el mismo lugar, único supuesto que le permitiría ponerse al frente de la explotación agrícola».

Como podemos observar, en la primera sentencia el Tribunal Supremo hace suyos los argumentos del Juzgado de Primera Instancia al entender que, a pesar de la literalidad de la cláusula que obliga al mejorado a «vivir en su compañía», la voluntad de la testadora se debe interpretar en el sentido de que «se había considerado suficientemente atendida por su hijo mejorado-legatario», ello a pesar de que el mejorado no sólo no viviese con ellos, sino que se mudase a otra Comunidad Autónoma, haciendo imposible cualquier tipo de cuidado, incluso ocasional, y a pesar, también, de que ni siquiera pasase las vacaciones en su casa, sino en la de sus suegros. Por otra parte, en la sentencia de la Audiencia Provincial de Asturias, se lleva a cabo una interpretación rígida de la cláusula por la que se obligaba a la hija a «vivir en compañía del testador y su esposa», y ni siquiera el hecho de haberlos cuidado y asistido efectivamente impidió que la cláusula se estimase ineficaz.

\subsection{Sobre el conocimiento o no de la condición impuesta}

En relación con la importancia o no de que el beneficiario-cuidador deba conocer la condición impuesta, comenzaremos analizando la SAP de A Coruña de 26 de septiembre de 2014 (JUR 2014, 262592). Este caso trata sobre el testamento otorgado por Raimundo en el año 2006 por el que legaba a su cónyuge el usufructo universal, a su hijo la legítima estricta, e instituía como heredero a su nieto, con la condición de cuidar y asistir al testador y a su esposa hasta el fallecimiento del último. En el relato fáctico de la 
sentencia se hace constar que algunos años antes de que el testador otorgase el testamento, en el 2003, el nieto-beneficiario había sufrido un grave accidente, siéndole reconocida una minusvalía del 65\% en el año 2005. Pues bien, dicho testamento fue impugnado por el hijo (a quien sólo se le había adjudicado la legítima estricta), toda vez que el nieto no había convivido con el testador ni le había cuidado desde el accidente. La Audiencia Provincial termina desestimando el caso, pues por un lado, el nieto no conocía la condición, y por otro, «fue instituido, pese a que, desde el año 2003, no vivía con sus abuelos, en testamento de 2006, el cual no fue revocado en vida del causante, con respecto al cual no se ha demostrado, a través de los correspondientes informes médicos, que, desde que otorgó dicho acto de última voluntad, estuviera totalmente incapacitado para testar de nuevo, dejando sin efecto la mentada institución a favor de su nieto, y todo ello dentro de un escenario de alejamiento afectivo y falta de relación entre el causante y su hijo, demandante en este proceso, que explica la pervivencia de la disposición mortis causa a favor del nieto, una vez respetada la legítima de aquél». Como se puede ver, la Audiencia Provincial no sólo tiene en cuenta la falta de conocimiento de la condición por parte del nieto, sino que hace una interpretación de la supuesta voluntad del testador para dejar sin efecto la condición de cuidados, los cuales no habían tenido lugar.

Otra sentencia que convendría analizar también es la SAP de Pontevedra de 17 de marzo de 2017 (JUR 2018, 1928). En este caso, la hermana de la testadora Nieves impugnó el testamento que esta había otorgado en 2009, en el que instituía heredero a su esposo Carlos bajo la condición de que si necesitase «atención por enfermedad, tanto mental como degenerativa, sea en la casa en la que habita donde se le cuide y se le facilite todo lo que necesite, en caso de no poder hacerlo su esposo, se contrate a una persona para que la atienda correctamente, negándose a que se le lleve a una residencia o geriátrico». Nieves había sido diagnosticada de problemas de deterioro mental en el año 2007 y permaneció en el domicilio familiar atendida y cuidada por su esposo hasta noviembre del 2012, momento en el que fue ingresada en una residencia, y posteriormente en otra, donde estuvo ingresada hasta su fallecimiento en enero de 2014. Lo que se cuestiona en la sentencia es si el demandado conocía dicha condición, de carácter potestativo y relativa a hechos pasados, pues su desconocimiento lo exoneraría: «no puede tenerse

Feminismo/s 38, July 2021, 307-329 
por incumplido aquello que se desconoce que se debe cumplir». Como quiera que no se pudo probar su conocimiento, la Audiencia Provincial desestimó el recurso.

Y ahora contrastemos estas dos sentencias mencionadas con la SAP de A Coruña de 25 de febrero de 2002 (JUR 2002, 136495). En este caso Manuel, un testador soltero y sin hijos, pero con tres hermanos (con uno de los cuales convivía desde hacía años) otorgó testamento el 29 de mayo de 1995 instituyendo como única y universal heredera de todos sus bienes a Susana Josefa, a quien el testador sólo conocía «por ser cliente del bar donde ella trabajaba», pero disponiéndolo «con la obligación de cuidar y asistir al testador hasta su fallecimiento». Esa misma noche «tuvo que entregar su alma». Pues bien, en la sentencia se afirma que «es indiscutible que, en el caso litigioso, la demandada no llegó a conocer antes de la muerte el contenido del testamento ni, por tanto, la condición que se le impuso para heredar»; sin embargo, se concluye que «lo supiera o no la demandada, lo cierto es que el hecho del que el testador condicionó o hizo depender la eficacia del nombramiento como heredera de aquélla no se cumplió, ni de modo propio o real o verdadero ni impropio o ficticio o legal»; por ello, procede «la apertura de la sucesión intestada o legítima y deferir la herencia en favor de los hermanos».

Como se puede observar, en este caso poco importa si la beneficiaria conocía o no la condición que la vinculaba a los cuidados. No vamos a negar que estemos de acuerdo con el resultado final, pues creemos que es necesario cierto tiempo mínimo de cuidados efectivos para que una cláusula de este tipo pueda tener valor; sin embargo, con lo que no podemos estar de acuerdo es con la argumentación jurídica, pues o se le da valor al hecho de conocer la condición impuesta o no se le da. Pero este no puede tratarse de un principio que se aplique únicamente cuando convenga, especialmente, para no desvirtuar las cláusulas testamentarias dispuestas en favor de cuidadores varones que no cumplen con las exigencias establecidas. Creemos que aquí la Audiencia Provincial probablemente llevase a cabo una interpretación moralista, contraria al principio de libertad de testar, del tipo de: ¿qué clase de hermano prefiere dejar su herencia a la camarera que le atiende en el bar que a su propia familia? Sin embargo, en nuestra opinión, no corresponde a los Tribunales hacer esta clase de interpretaciones, pues tal y como establece el artículo 763 CC, «el que no tuviere herederos forzosos [como ocurría en

Feminismo/s 38, July 2021, 307-329 
este caso] puede disponer por testamento de todos sus bienes o de parte de ellos en favor de cualquier persona que tenga capacidad para adquirirlos».

\subsection{Sobre la determinación de cuidados al testador}

Por último, y en relación con la determinación de cuidados al testador, convendría analizar la STS de 9 de mayo de 1990 (RJ 1990, 3696). En este caso, Melania había otorgado testamento en 1977 por el que mejoraba a su nieto Manuel, hijo de Ramona, y lo instituía heredero en el tercio de libre disposición, bajo condición «de que atienda al cuidado y asistencia de la testadora hasta su fallecimiento, y la obligación de abonar los gastos de entierro y funerales». En el remanente instituía herederas por partes iguales a sus dos hijas, con sustitución en favor de sus descendientes por estirpes. Melania falleció y fue enterrada en Dumbría, siendo atendida por su hija Ramona en su propia casa durante los últimos días; por ello, tanto Ramona como su hermana entendieron que no se había cumplido la condición expresada en el testamento y la impugnaron solicitando su nulidad. Lo que dice el TS es lo siguiente: «Su lectura revela que se trata de condición suspensiva, que impide adquirir el derecho si no se cumple, y que consiste en hechos pasados, puesto que han de tener existencia antes de que el testamento despliegue su eficacia. Además es potestativa, puesto que su cumplimiento depende de la voluntad de la persona del favorecido bajo condición (también de la voluntad de la causante). Así pues, siendo potestativa y de hechos pasados, naturalmente ha de conocerla el obligado a cumplirla para que su voluntad pueda determinar el cumplimiento. El Código prevé la hipótesis de condición suspensiva consistente en hechos posteriores a la muerte del causante y, además, potestativas (artículo 795), pero no contempla la condición suspensiva potestativa de hechos pasados. Por ello, en el caso de autos, ha de tenerse en cuenta lo dispuesto en el artículo 798, conforme al cual si el interesado en que se cumpla, que lo es, se presume, la causante, por propia voluntad cambia su domicilio, no por ello ha de entenderse que no se ha cumplido la condición, pues es él quien lo impidió y habrá de tenerse por cumplida y, por tanto, subsistente la disposición de bienes condicional, que, como bien dice la sentencia recurrida en calidad de obiter dicta, de haber querido la causante que perdiera eficacia habría revocado el testamento con otro posterior. Si 
la interesada en que no se cumpla, que son, también se presume, las hijas recurrentes, con su conducta produjeron el incumplimiento, también ha de tenerse por cumplida según el repetido artículo 798».

Es decir, según se desprende del Tribunal Supremo, poco importa si el nieto mejorado cuidó efectivamente a la testadora y cumplió con la condición establecida pues, de una parte, la testadora pudo haber cambiado el testamento ${ }^{5}$, de otra, las hijas, al impedir el cumplimiento de la condición cuidando a su madre, la dieron por cumplida ex artículo 798 CC (que establece que: «cuando el interesado en que se cumpla, o no, impidiere su cumplimiento sin culpa o hecho propio del heredero o legatario, se considerará cumplida la condición»). Nada se dice, sin embargo, si las hijas conocían la cláusula testamentaria e impidieron a propósito la condición de cuidados con la intención de impugnarla tras el fallecimiento de la testadora, o si simplemente decidieron cuidar a su madre, tal vez, aunque de nuevo nada se pueda saber del relato fáctico de la sentencia, debido a la pasividad del nieto beneficiario, o de su posible falta de diligencia a la hora de llevar a cabo los cuidados. Lo único que queda claro es que el Tribunal Supremo decide condenar a las hijas por su proactividad al decidir cuidar a su madre la testadora.

Pero si en un caso se condena la proactividad de las hijas, en otro se condena precisamente su falta de determinación, como ocurre en la SAP de A Coruña de 15 de mayo de 2019 (AC 2019, 846). En este caso, Noemí, viuda y con seis hijos (tres varones y tres mujeres), ordenó testamento en 2010 por el que hacía legados y disponía de la parte de libre disposición en favor del hijo o hijos que, en caso de necesidad, la atiendan y asistan hasta su fallecimiento, quedando instituidos los demás en la legítima que por ley corresponda. Y, en caso de no necesitar la asistencia referida, instituye herederos por partes iguales a cinco de sus hijos (tres hijos y dos hijas). En octubre de 2016 Noemí enferma y se contrata primero a una señora y después a otra para que la atiendan tanto por el día como por la noche (los tres hijos

5. Esta resolución hace que nos preguntemos por qué en este caso no se aplica el principio de irrelevancia de que «la testadora, pese al incumplimiento de la condición, no revocase el testamento, pues precisamente el carácter condicional de la obligación impuesta le hacía confiar razonablemente en la ineficacia de la institución de heredera contemplada en su testamento», tal y como se afirma en la STS de 30 de mayo de 2018 (RJ 2018, 2314).

Feminismo/s 38, July 2021, 307-329 
varones aportan dinero para los gastos). En enero de 2017 empeora por lo que sus tres hijos varones deciden ingresarla en una residencia geriátrica en Vigo y, como la pensión de la testadora no cubría por completo los costes, los tres hijos varones deciden poner 300 euros mensuales cada uno; uno de ellos (justamente al que sólo se le instituía en la legítima, Sebastián) remitió un burofax a sus tres hermanas solicitando que también colaborasen con los gastos. Finalmente, Noemí fallece en junio de 2017.

En la sentencia de primera instancia se determina que debe distribuirse la parte de libre disposición entre los tres hijos varones y se rechaza en todo caso la posibilidad de incluir en el pasivo los 7.504 euros que los tres hijos varones habían gastado en la residencia geriátrica en la que estaba ingresada la testadora, pese a la conformidad de las tres hijas, porque, por una parte, había precluido el trámite para variar el inventario, y, por otra, no son deudas de la herencia los pagos realizados voluntariamente por uno de los hijos a su causante, en cumplimiento voluntario de la obligación alimenticia. Posteriormente, la Audiencia Provincial afirma que valorada la prueba en su conjunto se llega a la misma conclusión que la juez de primera instancia: «Sea por la razón que fuere-distancia, situación económica, situación personal, otras obligaciones familiares, carácter...- lo cierto es que mientras los hijos adoptaron una actitud proactiva a la hora de prestar asistencia a su madre, las hijas mantuvieron una postura totalmente pasiva. Todo son discusiones, manifestaciones de discrepancias, promesas y propuestas alternativas. Pero quien adoptaba las soluciones, quien busca las señoras para cuidar a doña Noemí, quien aporta el dinero para pagar a esas cuidadoras, quien gestiona la residencia geriátrica y sufragaba el coste de las atenciones, son los hijos don Sebastián, don Oscar y don Víctor Manuel. Se puede comprender la situación personal de cada cual. Pero lo que no es posible es posponer siempre para el futuro la toma de decisiones y la adopción de medidas. Doña Noemí precisaba las atenciones cuando las requería, y no podía dilatarse en el tiempo prestarle la necesaria asistencia. Muestran su discrepancia con la aportación económica, pero claramente se les dijo que al menos reconociesen el importe que se pagaba para descontarlo en su día, y ni eso hicieron. Plantean llevársela a su casa y cuidarla allí, o bien ir a atenderla a su domicilio. Pero ninguna adoptó esa decisión realmente. Ninguna se la llevó, ni ninguna se mudó a su vivienda».

Feminismo/s 38, July 2021, 307-329 
En la sentencia se critica también la frase que tanto invocan de ofrecimiento a cuenta de la herencia futura: «Claramente se está diciendo que, si alguna no puede aportar numerario lo harían los otros hermanos por ella, y que lo devolvería cuando liquidasen la herencia. Se está ofreciendo un préstamo». Por todo ello, la sentencia determina que «estamos en presencia de una institución condicional. Y la condición fue cumplida exclusivamente por don Sebastián, don Óscar y don Víctor Manuel. Y por lo tanto el recurso debe ser desestimado». Sin embargo, se hace una importante reflexión, pues si en la sentencia de primera instancia se determinaba que el contador partidor debía efectuar cuaderno particional aplicando el tercio libre de la herencia a los tres hijos varones, en la SAP y con muy buen criterio, se observa que el testamento es claro en el sentido de que Sebastián no es nunca heredero, por lo que asignarle «una participación en la parte de libre disposición, cuando es mero legitimario, supone no respetar la voluntad de la causante»; en definitiva: «quizá sea conveniente replantearse este extremo a la hora de confeccionar el nuevo cuaderno, o en posibles impugnaciones ulteriores».

Las críticas que nos suscita esta sentencia son numerosas: por una parte, no llegamos a comprender la dureza con la que se juzga a las hijas por no colaborar en los gastos de los cuidados (a pesar de que se deduce del relato fáctico que se ofrecieron a cuidar a la testadora, aunque no llegaron nunca a hacerlo), infravalorando razones tan determinantes como las mencionadas (situación económica u otras obligaciones familiares). Como pudimos advertir en la introducción de este trabajo, a menudo las mujeres son las que se quedan en casa al cuidado de los hijos $u$ otros familiares, sin obtener a cambio ningún tipo de remuneración. Entonces, ¿no sería acaso comprensible que las hijas tuviesen razones de peso para no poder asumir el gasto de los cuidados de la testadora? En ningún caso se desprende del relato fáctico que las hijas, pudiendo, no quisieran participar en los gastos; más bien al contrario, lo que se dice es que las hijas entendían que los gastos asumidos por los hijos varones serían recompensados posteriormente con la herencia futura, incluyendo todas las cantidades como pasivo sucesorio (a lo que prestaron su conformidad, tal y como se desprende de la sentencia, aunque finalmente no fuese reconocida como deuda sucesoria); o que, en cualquier caso, se trataría de un préstamo que podrían resarcir con la herencia futura. Tanto la sentencia de primera instancia como la de apelación entendieron

Feminismo/s 38, July 2021, 307-329 
que los gastos por el cuidado de la testadora en sus últimos años de vida no eran deudas de la herencia, sino que se trataba de una obligación alimenticia. Esta afirmación es ciertamente rebatible, pues no es sino cuando Noemí enferma en el año 2016 que los hijos varones deciden contratar primero a dos señoras y después ingresarlas en una residencia, donde fallece en 2017, por lo que cabría interpretar que se trata de un gasto de última enfermedad que sí formaría parte del pasivo sucesorio (García Goldar, 2019, p. 105). Además, y en caso de tratarse realmente de una obligación alimenticia, tal y como se afirma en las dos sentencias, las cantidades debidas por cada uno de los alimentistas debería ser proporcionada a su caudal, es decir, a sus capacidades económicas (artículo 146 CC). Entonces, ¿por qué no se tuvo en cuenta la solvencia de cada uno de los hijos sobre esta cuestión?

Pero si hay algo que definitivamente nos descuadra por completo es que se considere cumplida la condición de asistencia por los hijos varones que nunca llegaron a cuidarla efectivamente, tal y como la testadora exigía; todo lo más que hicieron fue delegar su cuidado en otras personas: primero, en las dos señoras contratadas; segundo, con el ingreso de la testadora en una residencia geriátrica; sitio donde, dicho sea de paso, la testadora no deseaba estar, pues quería ser atendida por alguno de sus hijos, tal y como había establecido en el testamento. Si es que, de nuevo, se entiende que lo que hicieron los hijos fue un pago de alimentos, tal pago no puede considerarse hecho por voluntad propia, sino por exigencia de la ley; entonces, lo que existe no es cumplimiento de una condición testamentaria de cuidados, sino cumplimiento de un deber legal. Por ello, nos surge la duda: ¿es que se puede interpretar que hay cuidados efectivos cuando alguno o varios hijos pagan la diferencia entre la pensión del testador y lo que cuesta la residencia donde la están cuidando, a pesar del rechazo expreso del testador a su ingreso en uno de estos centros? ¿Y que, a sensu contrario, habrá falta de cuidados cuando alguno de los hijos no pueda pagar ese extra gasto, a pesar de que visiten al testador en la residencia geriátrica, tal y como hacían las hijas en este supuesto?

En nuestra opinión, este caso gira únicamente en torno a una cuestión económica: sólo los hijos varones satisficieron la diferencia entre lo que ganaba la testadora y lo que costaba cuidarla por otros; sólo ellos pagaron los gastos de la última enfermedad. Por ello, lo normal hubiese sido considerarlo 
una deuda sucesoria, a satisfacer con el patrimonio hereditario; o, en caso de insistir en que se trata de una obligación de alimentos, considerar que los hijos varones que asumieron la deuda tienen una acción de regreso frente a las hermanas, en función de lo que hubiesen tenido que pagar, en proporción a sus medios económicos. Sin embargo, que dicha deuda entre hermanos hubiese supuesto la exclusión de las hijas en la herencia de la testadora (salvaguardada su cuota de legítima) nos parece una consecuencia un tanto radical que puede ser además contraria a la voluntad de la testadora, que quería legar la herencia a quien la cuidase efectivamente, y en caso de no ser cuidada (por no necesitarlo, a lo que podría añadirse, ser cuidada por otros), que cinco de sus seis hijos fuesen los herederos.

Sin embargo, la dureza con la que se condena la falta de proactividad de las hijas en esta sentencia (cualidad esta, la proactividad, que se condena en la sentencia anteriormente citada) nos lleva, de nuevo, a cuestionarnos: ¿será que existe un doble rasero por parte de los Tribunales a la hora de evaluar los cuidados llevados a cabo por las mujeres frente a los llevados a cabo por hombres? ¿Se habría llegado a cualquiera de las soluciones planteadas si la situación hubiese ocurrido a la inversa? Es decir, en el caso anterior, ise habría conservado la validez de una cláusula en favor de la nieta bajo condición de cuidados, si finalmente quienes terminan cuidando a la testadora son los hijos?; y, ise hubiese excluido de la herencia a los hijos varones si sólo las hijas hubiesen prorrateado los gastos de la residencia?

\section{CONCLUSIONES Y VALORACIÓN PERSONAL}

La tarea de los cuidados, a familiares o a desconocidos, sigue siendo asumida en un gran porcentaje de los casos por mujeres. Su importancia social y económica es indudable, como demuestran los datos referidos, y todavía lo será más, debido al progresivo envejecimiento de la población. Tal vez por ello cada vez son más habituales las disposiciones testamentarias en favor de quien cuide al testador o bajo condición de cuidados.

En relación con el análisis jurisprudencial, nos ha sorprendido el hecho de que este tipo de cláusulas testamentarias en favor de quien cuide al testador no se hagan mayoritariamente en favor de mujeres, como cabría esperar. Esto probablemente se deba al hecho de que los testadores suelen disponer en

Feminismo/s 38, July 2021, 307-329 
favor de aquellas personas con las que le unen lazos familiares, aun cuando no vayan a ser estos beneficiarios varones quienes los cuiden efectivamente.

Además, creemos que en algunas sentencias es evidente la perpetuación de ciertos estereotipos de género, pues supuestos prácticamente idénticos se fallan en distinto sentido en función de si el beneficiario-cuidador es varón o mujer. Así ocurre, por ejemplo, en la manera en que los tribunales interpretan la condición de "vivir con el testador», en si es relevante o no que el beneficiario conociese la condición o no y, en general, en la determinación de la validez de la condición de cuidados aun cuando no los hubiese habido, la cual es mucho más laxa cuando el beneficiario es un varón.

No podemos dejar de llamar la atención sobre el hecho de que en dos de los supuestos examinados (condición de vivir en compañía del testador y determinación de la efectiva prestación de cuidados), son las sentencias del Tribunal Supremo las que presentan una fundamentación a nuestro modo de entender errática y dudosa con el (al menos aparente) propósito de reconocer la validez de las disposiciones testamentarias en favor de los varones. Pero esto no debe sorprendernos: al fin y al cabo, la Sala de lo Civil del Tribunal Supremo es la que tiene un peor porcentaje de mujeres magistradas ${ }^{6}$. La existencia de un techo de cristal en la judicatura española es evidente (García Rubio, 2014, p. 77), y dos son las posibles causas que lo explican (García Goldar, 2020, pp. 6-10): por una parte, la discriminación por razón de sexo en relación con el acceso a puestos discrecionales (Tribunales Superiores de Justicia, Tribunal Supremo); por otra, la dificultad para conciliar la vida familiar y laboral (Gómez Bahillo, Elboj Saso y Marcén Muñío, 2016, p. 204; Otero Parga, 2013, p. 469), debido en gran medida a la perpetuación de los ya mencionados estereotipos de género. Para muestra un botón: en el año

6. Forman parte de la Sala de lo Civil 10 magistrados, de los que sólo una es mujer: María de los Ángeles Parra Lucán. La Sala de lo Civil se convierte así en la Sala del Tribunal Supremo con un porcentaje más bajo de mujeres: apenas un 10\%. El pasado 4 de julio de 2019 se publicó una convocatoria para cubrir la plaza que dejaba vacante el magistrado Orduña Moreno (turno de juristas), por lo que la Comisión Permanente del Consejo General del Poder Judicial tuvo la oportunidad de corregir esta situación y procurar una presencia más equilibrada de mujeres y hombres en esta sala. Sin embargo, el resultado de la selección fue decepcionante: el candidato finalmente elegido fue un varón, a pesar de que existían candidatas femeninas con tan buen o mejor perfil. 
2017, el total de las 17 excedencias para el cuidado de hijos concedidas fueron solicitadas por juezas y magistradas (Consejo General del Poder Judicial). Cifras estas que demuestran que el I Plan Estratégico de la Carrera Judicial (2013) no ha alcanzado los objetivos propuestos; habrá que ver si el II Plan de 2020 arroja en el futuro datos más positivos.

A nuestro parecer, la necesaria introducción de la perspectiva de género en la jurisdicción civil será una quimera mientras el máximo órgano judicial en España siga perpetuando la imagen de la masculinización del Derecho. Kenney (2013) afirmaba que si queremos promover los derechos de las mujeres, tenemos que promover que haya más juezas; en nuestra opinión, no se trata sólo de hacer valer los derechos de las mujeres, sino de promover una organización judicial que represente a toda la sociedad en su conjunto: quién mejor para entender a una mujer o su situación que otra mujer. Y como dice Maule (2000, p. 296), un sistema judicial que no refleja a los miembros de una sociedad genera cada vez niveles más altos de desafecto y desilusión; sin embargo, a medida que más mujeres se vayan colocando en el banquillo, más fortalecido se verá el régimen democrático.

Si son las mujeres quienes soportan con harta frecuencia la carga de los cuidados familiares, deberían poder participar en la toma de decisiones sobre este y cualquier otro asunto que les afecte. Y para ello es necesaria la presencia equilibrada de mujeres (40-60\%) en los tribunales judiciales. Mientras ello no ocurra no habrá, en nuestra opinión, posibilidad alguna de lograr algún día la efectiva igualdad entre mujeres y hombres.

\section{REFERENCIAS BIBLIOGRÁFICAS}

Abellán García, A. y Pujol Rodríguez, R. (2015). Un perfil de las personas mayores en España, 2015. Indicadores estadísticos básicos. Informes Envejecimiento en red, 10 (enero). Recuperado de http://envejecimiento.csic.es/documentos/ documentos/enred-indicadoresbasicos15.pdf

Aguilera Rull, A. (2012). La actualidad del análisis feminista del derecho al hilo de pronunciamientos judiciales recientes. Anales de la Cátedra Francisco Suárez, 26, 183-209.

Consejo General del Poder Judicial. (2018). Informe sobre la estructura de la Carrera judicial a 1 de enero de 2018. Recuperado 30 de abril de 2020 de www.poderjudicial.es/stfls/ESTADISTICA/FICHEROS/2002\%20Caracteristicas\%20

Feminismo/s 38, July 2021, 307-329 
Sobre la necesidad de introducir la perspectiva de género en la jurisdicción civil española

de\%20jueces\%20y\%20magistrados/A\%C3\%Blos\%20anteriores/Carrera\%20 Judicial\%202018.pdf

Cruz Roja. El 89 por ciento de las personas cuidadoras es mujer. Recuperado 14 de septiembre de 2020, de www2.cruzroja.es/-/ el-89-por-ciento-de-las-personas-cuidadoras-es-mujer

Facal Fondo, T. y Torrens Calle, P. (2010). Cambios sociológicos en la familia con repercusión en el Derecho de Sucesiones. En A. L. Rebolledo Varela (Dir.), La familia en el Derecho de Sucesiones: cuestiones actuales y perspectivas de futuro (pp. 43-82). Dykinson.

García Goldar, M. (2019). La liquidación de la herencia en el Código Civil español: especial referencia a las deudas sucesorias desconocidas o sobrevenidas. Boletín Oficial del Estado.

García Goldar, M. (2020). The glass ceiling at the highest levels of the Spanish judiciary. International Journal of the legal profession, 27, 1-15. https://doi.org /10.1080/09695958.2020.1775601

García Rubio, M. P. (2014). Comprender y transmitir el derecho de las mujeres. En C. Mesa Marrero, M. C. Grau Pineda (Coords.) Mujeres, contratos y empresa desde la igualdad de género (pp. 77-92). Tirant lo Blanch.

García Rubio, M. P. (2020). Perspectiva de género en la pandemia del COVID19. Recuperado 25 de marzo 2020, de www.valedordopobo.gal/es/essential_grid/perspectiva-de-genero-en-la-pandemia-del-covid-19-por-maria-paz-garcia-rubio-catedratica-de-derecho-civil-de-la-universidad-de-santiago-de-compostela/

Gómez Bahillo, C., Elboj Saso, C. y Marcén Muñóo, C. (2016). The feminization of the Spanish judiciary. Convergencia: revista de ciencias sociales, 70, 199-226.

Kenney, S. (2013). Gender and Justice: Why Women in the Judiciary Really Matter. Routledge. https://doi.org/10.4324/9780203122297

Maule, L. (2000). A different voice. The feminine jurisprudence of the Minnesota State Supreme Court. Buffalo Women's Law Journal, 9, 295-316.

Mier Villarías, I., Romeo Pérez, Z., Canto Combarro, A. y Mier Villarías, R. (2007). Interpretando el cuidado. Por qué cuidan sólo las mujeres y qué podemos hacer para evitarlo. Zerbitzuan: Gizarte zerbitzuetarako aldizkaria = Revista de servicios sociales, 42, 29-38.

Otero Parga, M. (2013). Una mujer juez. A propósito del Plan 14/02/2013 de Igualdad de la Carrera Judicial. Dereito: revista xurídica da Universidade de Santiago de Compostela, 22, 441-474. 
Pau Pedrón, A. (2020). El principio de igualdad y el principio de cuidado, con especial atención a la discapacidad. Revista de Derecho civil, 6(1), 3-29.

Red2Red Consultores. (2008). Cuidados a personas dependientes prestados por mujeres: valoración económica. Instituto de la Mujer.

Rogero García, J. (2010). Las consecuencias del cuidado familiar sobre el cuidador: Una valoración compleja y necesaria. Index de enfermería: información bibliográfica, investigación y humanidades, 19(1), 47-50. https://doi. org/10.4321/S1132-12962010000100010

Rubio, R. (2004). Mujeres cuidadoras: los cuidados, todavía, tienen rostro femenino. Sesenta y más, 223, 46-51.

Sociedad Española de Geriatría y Gerontología. El 89\% de los cuidadores en España son mujeres y en el $47 \%$ de los casos, el cuidador principal es un familiar. Recuperado 3 de noviembre de 2016, de www.segg.es/institucional/2016/11/03/el-89-por-ciento-de-los-cuidadores-en-espa\%C3\%Bla-sonmujeres-y-en-el-47-por-ciento-de-los-casos-el-cuidador-principal-es-unfamiliar

Suso Araico, A. y Velasco Gisbert, M. L. (2009). Valoración económica de los cuidados a personas dependientes. Zerbitzuan: Gizarte zerbitzuetarako aldizkaria $=$ Revista de servicios sociales, 45, 73-81.

\section{RELACIÓN DE SENTENCIAS ANALIZADAS (ORDENADAS POR ÓRGANOS Y CRONOLÓGICAMENTE):}

1. SJPI de Celanova (Orense) de 22 noviembre de 2012 (JUR 2014, 282406)

2. SAP de Asturias de 3 de febrero de 1995 (AC 1995, 393)

3. SAP de A Coruña de 25 de febrero de 2002 (JUR 2002, 136495)

4. SAP de Pontevedra de 5 junio de 2003 (JUR 2004, 2187)

5. SAP de Sevilla de 9 junio de 2009 (JUR 2010, 14320)

6. SAP de Barcelona de 26 de octubre de 2011 (AC 2014, 2154)

7. SAP de Alicante de 30 de mayo de 2012 (AC 2012, 1285)

8. SAP de A Coruña de 26 de septiembre de 2014 (JUR 2014, 262592)

9. SAP de Jaén de 6 de noviembre de 2015 (AC 2016, 137)

10. SAP de Pontevedra de 17 de marzo de 2017 (JUR 2018, 1928)

11. SAP de Guipúzcoa de 26 abril de 2018 (AC 2018, 1045)

12. SAP de Ciudad Real de 22 octubre de 2018 (JUR 2019, 2021)

13. SAP de A Coruña de 15 de mayo de 2019 (AC 2019, 846)

14. STS de 12 de junio de 1956 (RJ 1956, 2482) 
15. STS de 25 de marzo de 1957 (AC 2018, 1045)

16. STS de 9 de mayo de 1990 (RJ 1990, 3696)

17. STS de 21 de enero de 2003 (RJ 2003, 604)

18. STS de 3 de diciembre de 2009 (RJ 2010, 269)

19. STS de 18 de julio de 2011 (RJ 2011, 5217)

20. STS de 30 mayo de 2018 (RJ 2018, 2314) 